\title{
Development of a Predictive Model to Improve the Hardness of Mild Steel Welded Joint
}

\author{
0. 0. Ogbeide1, L. M. Ebhota ${ }^{2}$ \\ ${ }^{1}$ Department of Production Engineering, University of Benin, Benin City, Nigeria \\ ${ }^{2}$ Groove Engineering \& Integrated Services Limited, Lagos, Nigeria \\ Email: osarobo.ogbeide@uniben.edu, larryebhota@yahoo.com,grooveengineeringservices@gmail.com
}

How to cite this paper: Ogbeide, O.O. and Ebhota, L.M. (2021) Development of a Predictive Model to Improve the Hardness of Mild Steel Welded Joint. Engineering, 13, 215-223.

https://doi.org/10.4236/eng.2021.134016

Received: March 16, 2021

Accepted: April 27, 2021

Published: April 30, 2021

Copyright (c) 2021 by author(s) and Scientific Research Publishing Inc. This work is licensed under the Creative Commons Attribution International License (CC BY 4.0).

http://creativecommons.org/licenses/by/4.0/

(c) (i) Open Access

\begin{abstract}
Structural integrity of weldment is greatly influenced by its process parameters and usually, it is expected for a welded joint to be stronger than its parent metal, but in actual fact, most failures occur at the welded joints and it is mostly due to poor combination of process parameters or inexperience of the welder. This poor combination leads to poor hardness exhibited at the welded joint. The aim of this study is to predict and improve the hardness of mild steel welded zone using the tungsten inert gas (TIG) welding process. Response Surface Methodology (RSM) was employed to analyze the welded response. 200 pieces of mild steel coupons measuring $27.5 \times 10 \times 10 \mathrm{~mm}$ were prepared and used for the experiment, the experiment was performed 20 times, using 5 specimens for each run, after which the hardness was measured and results analyzed respectively. The study produced eighteen (18) optimum results with the best selected to produce a material hardness of 299.269 $\mathrm{N} / \mathrm{mm}^{2}$ with desirability of $95.6 \%$, resulting from current of $120 \mathrm{amp}$, voltages of 20 and gas flow rate of $12 \mathrm{~L} / \mathrm{min}$.
\end{abstract}

\section{Keywords}

RSM, TIG, Mild Steel, Contour Plot

\section{Introduction}

The tendencies of any materials to resists penetration, abrasion, scratching or cutting are regarded as hardness. It is the property by which material resists permanent deformation [1]. The automobile and shipbuilding industries employ a substantial amount of mild steel in making parts, some of these parts involve bending and forming. The relative malleability and softness of mild steel materials give room to an outstanding ductility and toughness of the material [2] and 
[3]. This also increases its machinability and weldability of the material. Welding is the most extensively used method of metal joining, in various industries like oil and gas, rig design and marine transportation, construction, automobile industries etc. [4]. Due to the quick joining process that creates a permanent waterproof bond and provides better cost saving, its applications are numerous. Welding operations have an overall weight reduction as compared to other joining methods. The structural integrity of the weldment is greatly influenced by its process parameters and usually, it is expected for a welded joint to be stronger than its parent metal, but in actual fact, most failures occur at the welded joints and it is mostly due to poor combination of poor process parameters or inexperience of the welder [5] and [6]. Poor weld reduces the hardness and scratch resistance of weldment, it also encourages high corrosion activities [7].

It has been proven by several researchers that the choice of welding input process parameters can alter the quality of the weldment, therefore, optimizing these process parameters to obtain the best weld quality and multi-response properties cannot be over emphasized [8] and [9]. This research aims at predicting and optimizing the Hardness of mild steel weld using tungsten inert gas (TIG) welding process and design expert 11.

\section{Materials and Methods}

\subsection{Materials}

The key parameters considered in this work are welding current, welding voltage and gas flow rate [10]. The range of the process parameters is shown in Table 1. The TIG welding and test were conducted at the Department of Welding and fabrication technology, Petroleum Training Institute (PTI), Warri, Delta State, Nigeria.

The selected input parameters have the upper (+) and lower limits (-). The limits of the four welding variables are shown in Table 1.

\subsection{Methods}

200 pieces of mild steel coupons measuring $27.5 \times 10 \times 10 \mathrm{~mm}$ were used for the experiments, the experiment was performed 20 times, using 5 specimens for each run for hardness test specimen presented in Figure 1. The hardness of the welded specimens was measured by means of Brinell hardness tester. The procedure adopted is as follows:

Table 1. Welding process parameters limits.

\begin{tabular}{ccccc}
\hline Process parameters & Unit & Symbol & Low (-) & High (+) \\
\hline Welding Current & Amp & I & 120 & 170 \\
Welding Voltage & Volts & V & 20 & 25 \\
Gas Flow Rate & Lit/mill & F & 12 & 14 \\
\hline
\end{tabular}




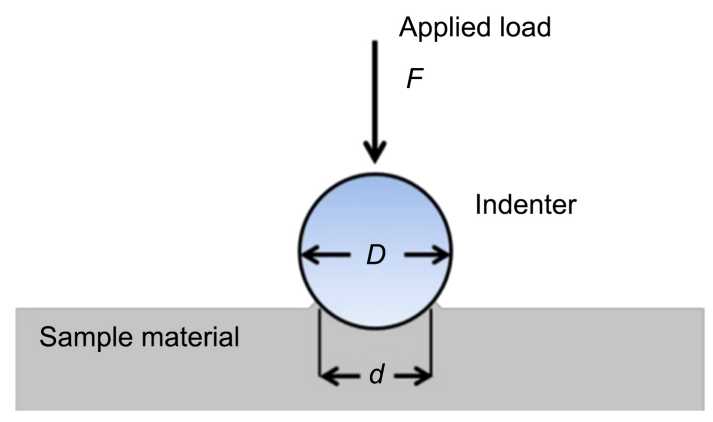

Figure 1. Working principle of Brinell hardness test.

1) The indenter is pressed into the sample by an accurately controlled test force.

2) The force is maintained for a specific dwell time, normally 10 - 15 seconds.

3) After the dwell time is complete, the indenter is removed leaving a round indent in the sample.

4) The size of the indent is determined optically by measuring two diagonals of the round indent using a portable microscope.

5) The Brinell hardness number is a function of the test force divided by the curved surface area of the indent. The indentation is considered to be spherical with a radius equal to half the diameter of the ball. The average of the two diagonals is used in the following formula to calculate the Brinell hardness.

\section{Results and Discussion}

\subsection{Results}

In this study, twenty (20) experimental runs were carried out, each experimental run, comprising the current, voltage and gas flow rate used to join two pieces of mild steel plates measuring $55 \mathrm{~mm} \times 10 \mathrm{~mm} \times 10 \mathrm{~mm}$. The hardness test was measured and results were presented in Table 2 .

Table 3 presents the model summary statistics for the hardness test, the quadratic model, was selected as the best model since it has the highest Adjusted and Predicted $\mathrm{R}^{2}$ among listed sources whereas, the cubic source was aliased.

Table 4 shows the ANOVA for quadratic model used to analyze the hardness test with coded factors of $\mathrm{A}, \mathrm{B}$ and $\mathrm{C}$ representing current, voltage and gas flow rate which was used to develop the quadratic model that mimics the behavior of the weldment as presented in Equation (1). The Sum of squares from the ANOVA table has a Type III Partial with the Model F-value of 6.87 which indicates a significant model. This means that there is only a $0.29 \%$ chance that an F-value this large could result from noise.

The fit statistics for the hardness test are presented in Table 5 with $\mathrm{R}^{2}$, Adjusted $R^{2}$, Predicted $R^{2}$ and the Adequate Precision. Signal to noise ratio $(S / N)$ is measured using the Adequate precision, according to literature, it is generally recommended to have an adequate precition value greater than four (4) to have a desirable model. 
Table 2. Experimental result for the hardness test.

\begin{tabular}{|c|c|c|c|c|}
\hline Run & $\begin{array}{l}\text { A: Welding } \\
\text { Current }\end{array}$ & $\begin{array}{l}\text { B: Welding } \\
\text { Voltage }\end{array}$ & $\begin{array}{c}\text { C: Gas Flow } \\
\text { Rate }\end{array}$ & Hardness Test \\
\hline & Amp & Volts & Lit/mill & $\mathrm{N} / \mathrm{mm}^{2}$ \\
\hline 1 & 145 & 22.5 & 13 & 255.493 \\
\hline 2 & 145 & 22.5 & 13 & 246.792 \\
\hline 3 & 187 & 22.5 & 13 & 281.596 \\
\hline 4 & 145 & 22.5 & 11 & 280.014 \\
\hline 5 & 170 & 20 & 12 & 254.702 \\
\hline 6 & 145 & 18 & 13 & 249.956 \\
\hline 7 & 170 & 25 & 14 & 288.478 \\
\hline 8 & 120 & 20 & 14 & 256.284 \\
\hline 9 & 170 & 25 & 12 & 264.194 \\
\hline 10 & 120 & 25 & 12 & 293.461 \\
\hline 11 & 120 & 20 & 12 & 295.834 \\
\hline 12 & 102 & 22.5 & 13 & 302.162 \\
\hline 13 & 170 & 20 & 14 & 238.091 \\
\hline 14 & 145 & 22.5 & 14 & 252.329 \\
\hline 15 & 145 & 22.5 & 13 & 250.747 \\
\hline 16 & 145 & 22.5 & 13 & 276.059 \\
\hline 17 & 145 & 26 & 13 & 271.313 \\
\hline 18 & 145 & 22.5 & 13 & 259.448 \\
\hline 19 & 120 & 25 & 14 & 283.969 \\
\hline 20 & 145 & 22.5 & 13 & 238.091 \\
\hline
\end{tabular}

Table 3. Model summary statistics from the hardness test.

\begin{tabular}{ccccccc}
\hline Source & Std. Dev. & $\mathbf{R}^{2}$ & Adjusted $\mathbf{R}^{2}$ & Predicted $\mathbf{R}^{2}$ & PRESS & \\
\hline Linear & 17.03 & 0.3653 & 0.2463 & 0.008 & 7254.96 & \\
2FI & 16.32 & 0.5267 & 0.3083 & 0.0845 & 6695.01 & \\
Quadratic & 10.09 & $\mathbf{0 . 8 6 0 7}$ & $\mathbf{0 . 7 3 5 4}$ & $\mathbf{0 . 6 4 0 3}$ & $\mathbf{2 6 3 0 . 8 3}$ & Suggested \\
Cubic & 11.89 & 0.8841 & 0.633 & 0.3961 & 4416.61 & Aliased \\
\hline
\end{tabular}

Table 4. ANOVA for quadratic model of the hardness test.

\begin{tabular}{|c|c|c|c|c|c|}
\hline Source & $\begin{array}{l}\text { Sum of } \\
\text { Squares }\end{array}$ & df & $\begin{array}{l}\text { Mean } \\
\text { Square }\end{array}$ & F-value & p-value \\
\hline Model & 6294.74 & 9 & 699.42 & 6.87 & significant \\
\hline A-Welding Current & 1031.19 & 1 & 1031.19 & 10.12 & 0.0098 \\
\hline B-Welding Voltage & 1073.99 & 1 & 1073.99 & 10.54 & 0.0088 \\
\hline C-Gas Flow Rate & 566.14 & 1 & 566.14 & 5.56 & 0.0401 \\
\hline
\end{tabular}


Prediction of Hardness test can be done using the Equation (1), the plot of the predicted versus the experimental is presented in Figure 2.

$$
\begin{aligned}
\mathrm{HT}= & 254.51-8.69 \mathrm{~A}+8.87 \mathrm{~B}-6.44 \mathrm{C}+4.32 \mathrm{AB}+7.09 \mathrm{AC}+8.87 \mathrm{BC} \\
& +12.79 \mathrm{~A}^{2}+1.74 \mathrm{~B}^{2}+3.70 \mathrm{C}^{2}
\end{aligned}
$$

From the plot presented in Figure 2, the predicted and actaul, have the same minimum value of $220 \mathrm{~N} / \mathrm{mm}^{2}$ and maximum of $320 \mathrm{~N} / \mathrm{mm}^{2}$. The positive slope with minimal scattering along the slope shows a good agreement between our model and the experimental response.

The 3D surface plot presented in Figure 3, shows the effect of current and voltage on hardness of the mild steel specimen. To design above the predicted value, one should target the point dotted in wine. The 3D surface plot gives an overall view of the design space for informed decision. The blue region indicates the region with the weakest hardness strength. From the plot, the toughest area lies in the green region of the plot.

To optimize the Hardness of the material, deign expert 11 interphase for optimization was fixed to maximize in Figure 4 under hardness test.

Table 5. Fit statistics for the hardness test.

\begin{tabular}{cccc}
\hline Std. Dev. & 10.09 & $\mathbf{R}^{2}$ & 0.8607 \\
Mean & 266.95 & Adjusted $\mathbf{R}^{2}$ & 0.7354 \\
C.V. \% & 3.78 & Predicted $\mathbf{R}^{2}$ & 0.6403 \\
& & Adeq Precision & 8.7792 \\
\hline
\end{tabular}

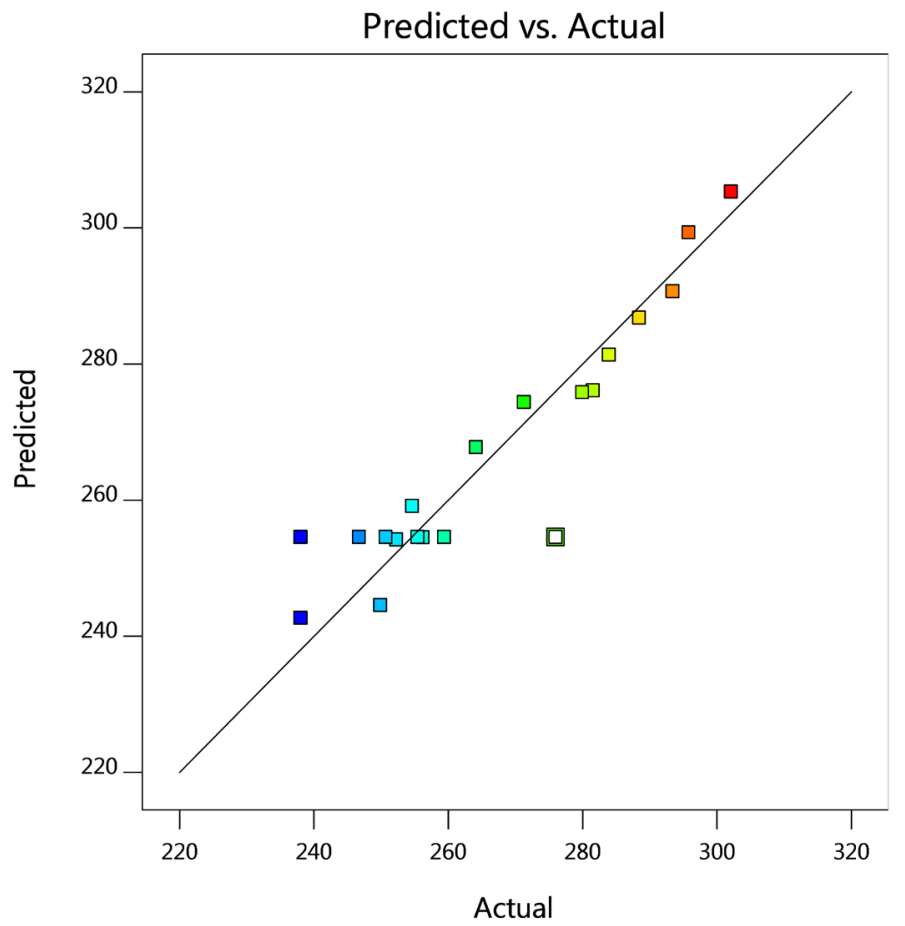

Figure 2. Plot of predicted versus actual hardness test. 


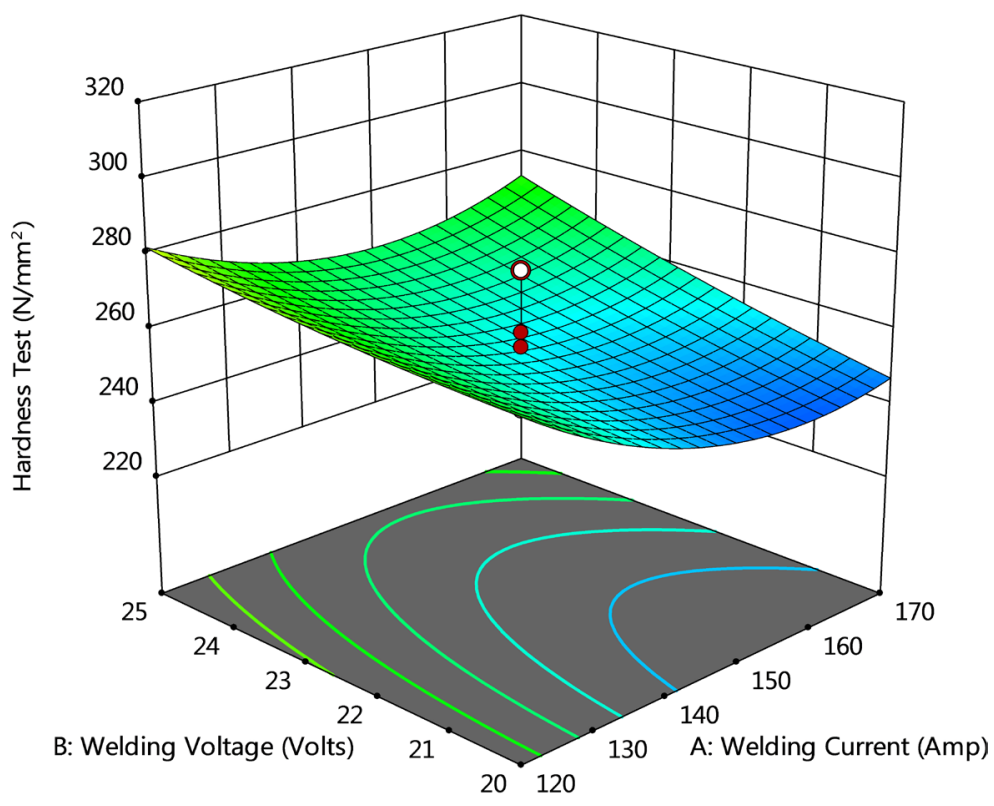

Figure 3. Surface plot for effect of current and voltage on the hardness test.

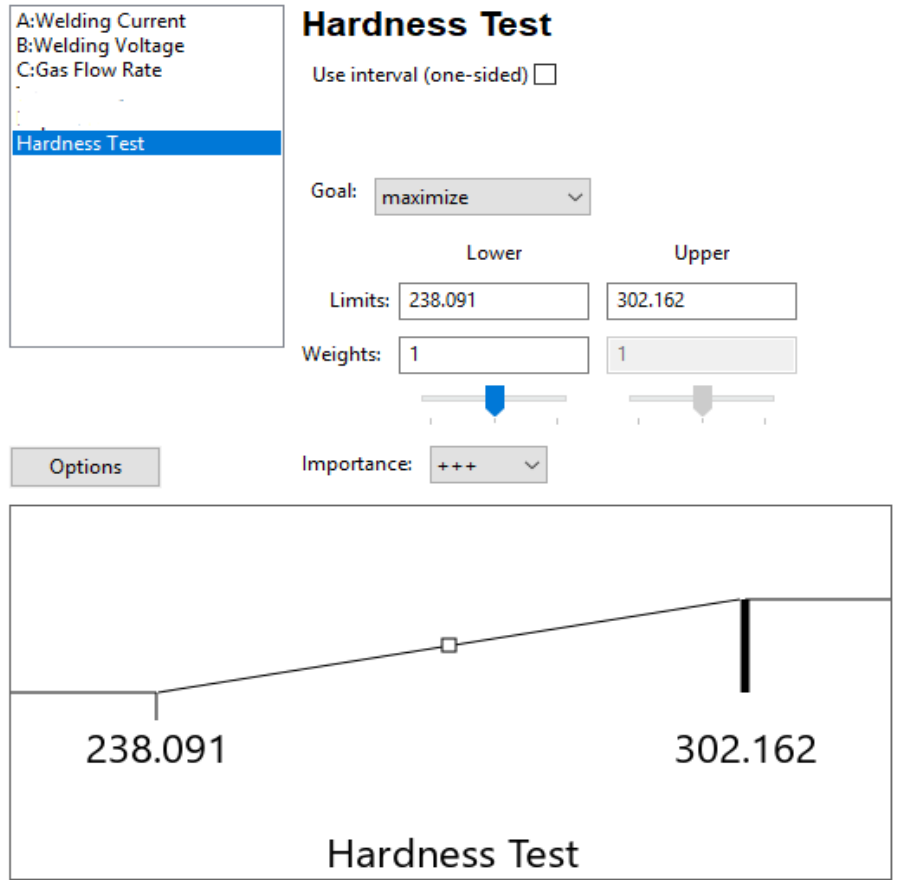

Figure 4. Interphase of numerical optimization model for Hardness test.

The interface of numerical optimization is used to define the objective function (minimize or maximize), which is used to defines the lower and upper limit of the response with the level of importance indicated. In other to maximize the material hardness, the weight leans towards the higher limit of 302.162 as seen in Figure 4.

The numerical optimization from Figure 4 was employed in producing eighteen (18) optimal solutions presented in Table 6. 
From the results in Table 6, it was observed that current of $120 \mathrm{Amp}$, voltage of 20.00 volt and gas flow rate of $12.00 \mathrm{~L} / \mathrm{min}$ produced a weld material with good hardness of $299.269 \mathrm{~N} / \mathrm{mm}^{2}$. This solution obtained was selected by design expert as the optimal solution with a desirability value of $97.30 \%$.

The contour plots showing the hardness response variable of the material against the optimized value of the input variable are presented in Figure 5. To maximize the hardness of the material, the red region on the plot in Figure 5 should be targeted. This region of optimal responses for increased hardness can be achieved by the use of the optimal process parameters of Table 6 .

\subsection{Discussion}

The ANOVA in Table 4 shows a P-values of 0.0029 which is less than 0.0500 , this indicates a significant model. It was still observed in that same table that the coded variables of $\mathrm{A}, \mathrm{B}, \mathrm{C}, \mathrm{BC}$ and $\mathrm{A}^{2}$ were significant model terms, this is because their respective $p$-values were less than 0.05 . In other to develop a robust mathematical model for the material hardness, most of the input variables (coded variables) in Equation (1) need to have a p-value less than 0.05 for the model to be significant. The Fit statistics in Table 5 show an $\mathrm{R}^{2}$ of 0.8607 , Predicted and Adjusted $\mathrm{R}^{2}$ of 0.6403 and 0.7354 . according to literature, the difference between the Predicted and Adjusted $\mathrm{R}^{2}$ must be less than 0.2 for good agreement to be established. In our case, 0.0951 value was obtained, showing a reasonable agreement. The Adequate Precision of 8.779 was obtained, this shows a good adequate signal. With a pass mark, obtained from the ANOVA and the Fit statistics tables, a mathematical expression for the material hardness was developed in Equation (1) which was used to navigate the design space.

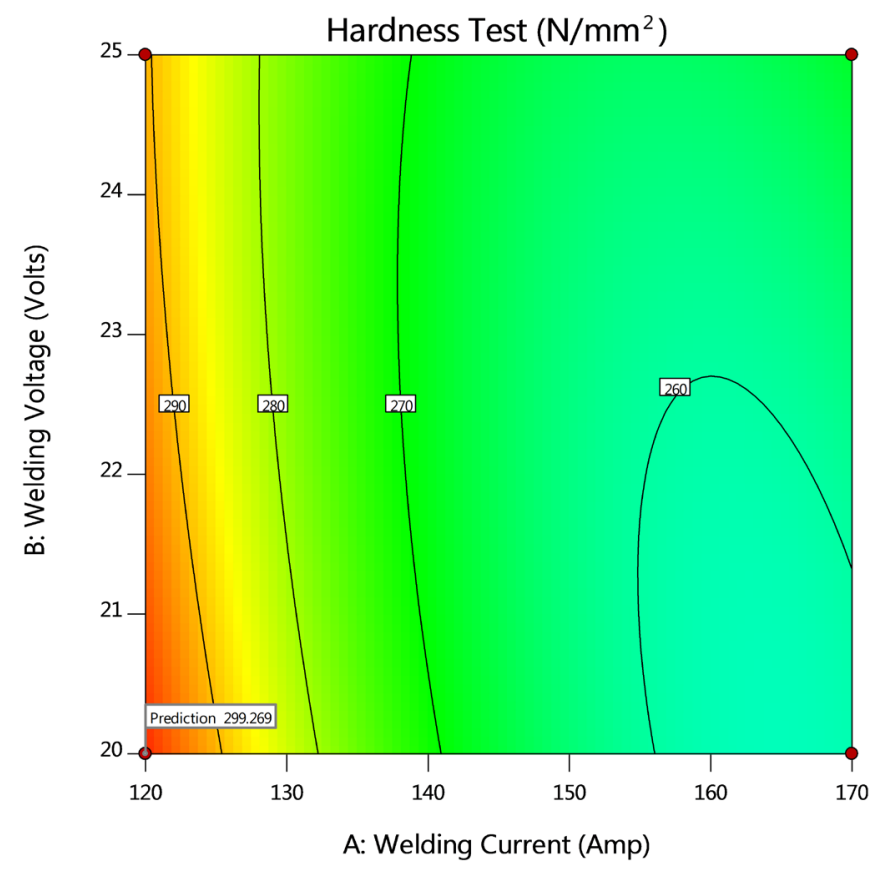

Figure 5. Contour plot for predicting the hardness of the material. 
Table 6. 18 optimum solutions found.

\begin{tabular}{|c|c|c|c|c|c|c|}
\hline Number & $\begin{array}{l}\text { Welding } \\
\text { Current }\end{array}$ & $\begin{array}{l}\text { Welding } \\
\text { Voltage }\end{array}$ & $\begin{array}{c}\text { Gas Flow } \\
\text { Rate }\end{array}$ & $\begin{array}{c}\text { Hardness } \\
\text { Test }\end{array}$ & Desirability & \\
\hline 1 & 120 & 20 & 12 & 299.269 & 0.956 & Selected \\
\hline 2 & 120 & 20.036 & 12 & 299.157 & 0.954 & \\
\hline 3 & 120.01 & 20 & 12.007 & 299.039 & 0.952 & \\
\hline 4 & 120.177 & 20 & 12 & 298.946 & 0.951 & \\
\hline 5 & 120 & 20.119 & 12 & 298.9 & 0.949 & \\
\hline 6 & 120 & 20 & 12.015 & 298.838 & 0.949 & \\
\hline 7 & 120 & 20.162 & 12 & 298.771 & 0.947 & \\
\hline 8 & 120.462 & 20 & 12 & 298.429 & 0.943 & \\
\hline 9 & 120 & 20 & 12.029 & 298.407 & 0.942 & \\
\hline 10 & 120.715 & 20 & 12 & 297.972 & 0.936 & \\
\hline 11 & 121.046 & 20 & 12 & 297.382 & 0.926 & \\
\hline 12 & 120 & 20.718 & 12 & 297.171 & 0.918 & \\
\hline 13 & 122.705 & 20 & 12 & 294.477 & 0.88 & \\
\hline 14 & 120 & 21.773 & 12 & 294.612 & 0.874 & \\
\hline 15 & 120 & 21.838 & 12 & 294.474 & 0.872 & \\
\hline 16 & 120 & 22.318 & 12 & 293.532 & 0.856 & \\
\hline 17 & 120 & 22.599 & 12 & 293.039 & 0.848 & \\
\hline 18 & 120 & 22.627 & 12 & 292.994 & 0.848 & \\
\hline
\end{tabular}

To maximum the material hardness, the upper limit of $302.162 \mathrm{~N} / \mathrm{mm}^{2}$ in Figure 4 was targeted. This target produced eighteen (18) optimum results in Table 6.

The contour plots in Figure 5 show the effect of voltage and current on the material hardness. It can be deduced from the plot that to maximize the material hardness, effort should be made toward the red region of Figure 5. The eighteen (18) optimum results in Table 6 are all concentrated around the red region on the contour plot. In same table, the optimum result for the material hardness was obtained as current of $120 \mathrm{amp}$, voltages of 20 and gas flow rate of 12 to produce a material hardness of $299.269 \mathrm{~N} / \mathrm{mm}^{2}$ with desirability of 0.956 or 95.6\%. This shows that RSM was robust enough for predicting.

\section{Conclusions}

In this study, mathematical model for material hardness is presented in Equation (1), using the Tungsten Inert Gas (TIG) welding process with three (3) process parameters, namely: current, voltage and gas flow rate have been developed. The outcomes obtained indicate that current of $120 \mathrm{Amp}$, voltage of 20 volt and gas flow rate of $12 \mathrm{~L} / \mathrm{min}$ will produce a weld with material hardness of 299.269 $\mathrm{N} / \mathrm{mm}^{2}$. This optimum solution was selected at a desirability of $95.60 \%$. 
Weld current is found to have a greater influence on the material hardness as compared to voltage and gas flow rate at a moderate level.

\section{Conflicts of Interest}

The authors declare no conflicts of interest regarding the publication of this paper.

\section{References}

[1] Tomkowski, R., Jonsson, S., Lundin, P. and Nerman, P. (2017) Penetration Depth Investigation of Barkhausen Noise Signal for Case-Hardened Components. 12 th International Conference on Barkhasuen Noise and Micromagnetic Testing, Fraunhofer Institute for Ceramic Technologies and Systems IKTS, Dresden.

[2] Achebo, J.I. (2011) Optimization of GMAW Protocols and Parameters for Improving Weld Strength Quality. 2011 World Congress on Engineering. International Conference of Manufacturing Engineering and Engineering.

[3] Achebo, J.I. (2012) Complex Behavior of Forces Influencing Molten Weld Metal Flow Based on Static Force Balance Theory. Physics Procedia, 25, 317-324. https://doi.org/10.1016/j.phpro.2012.03.090

[4] Kumar, V. (2011) Modeling of Weld Bead Geometry and Shape Relationships in Submerged Arc Welding Using Developed Fluxes. Jordan Journal of Mechanical and Industrial Engineering, 5, 461-470.

[5] Olabi, A.G. and Hashmi, M.S.J (1995) The Effect of Post-Weld Heat-Treatment on Mechanical Properties and Residual-Stresses Mapping in Welded Structural Steel. Journal of Materials Processing Technology, 55, 117-122. https://doi.org/10.1016/0924-0136(95)01794-1

[6] Etin-Osa, C.E. and Achebo, J.I. (2017) Analysis of Optimum Butt Welded Joint for Mild Steel Components Using FEM (ANSYS). American Journal of Naval Architecture and Marine Engineering, 2, 61-70.

http://www.sciencepublishinggroup.com/j/ajname https://doi.org/10.11648/j.aas.20170206.12

[7] Etin-Osa, D. and Etin-Osa, C.E. (2019) Forensic Science and the Nigerian Society. Journal of Nuclear Sciences. http://jns.ankara.edu.tr

[8] Elgueder, J., Roucoules, L., Rouhaud, E. and Cochennec, F. (2011) Integration of Residual Stresses in the Design of Mechanical Parts. Materials Science Forum, 681, 255-260. https://www.scientific.net/MSF.681.255 https://doi.org/10.4028/www.scientific.net/MSF.681.255

[9] Withers, P.J. and Bhadeshia, H.K.D.H. (2014) Residual Stress. Part 1-Measurement Techniques. Materials Science and Technology, 17, 355-365. https://doi.org/10.1179/026708301101509980

[10] Anowa, H.D., Achebo, J.I., Ozigagun, A. and Etin-Osa, E.C. (2018) Analysis of Weld Molten Metal Kinematic Viscosity of Tig Mild Steel Weld. International Journal of Advanced Engineering and Management Research, 3, 14-30. 